\title{
The Role of Oxidative Stress Markers in Acute Respiratory Distress Syndrome
}

\author{
Marina Sarkele*,**, Olegs Sabelnikovs*,*, Indulis Vanags*,**, Agnese Ozolina*, Andrejs Skesters***, Alise Silova*** \\ * Department of Anaesthesiology and Reanimatology, Riga Stradins University, Riga, Latvia \\ ** Department of Anaesthesiology and Reanimatology, Pauls Stradins Clinical University Hospital, Riga, Latvia \\ *** Laboratory of Biochemistry, Riga Stradins University, Riga, Latvia
}

\begin{abstract}
Summary
Introduction. Patients in the intensive care unit (ICU) are likely to suffer from acute respiratory failure (ARF) with a risk of developing acute lung injury (ALI) and its more severe condition, acute respiratory distress syndrome (ARDS) with $30-50 \%$ mortality. Evidence shows, that important role in ARDS pathophysiology may play an imbalance between oxidant and antioxidant species. Oxidative stress is well established in adult critical illnesses characterized by systemic inflammatory response.
\end{abstract}

Aim of the study was to investigate the influence of oxidative stress species on developing of acute respiratory distress syndrome in patients at risk.

Materials and methods. The study was conducted in Pauls Stradins Clinical University Hospital ICU during 6 months in 2013 and approved by ethics committee. There were included 15 ARDS risk patients over 18 years of age with mechanical lung ventilation (MLV) over 24 hours and massive blood component transfusions, acute severe pancreatitis, pneumonia or sepsis. Blood samples were taken three times during observational period- first sample were taken just exactly after inclusion, second sample- on 4th and the last sample- on 7th day after inclusion. The developing of ARDS were diagnosed using revised diagnostic criteria according to the Berlin definition. Reactive oxygen species were measured in plasma using manual or automatic spectrophotometry.

Results. Among included patients $82.4 \%$ were males with the mean age 49.3 years, for female 67 years. The most popular diagnosis was acute severe pneumonia $(n=5 ; 33.3 \%)$, followed by patients with sepsis $(n=4 ; 26.7 \%)$ and acute severe pancreatitis $(\mathrm{n}=4 ; 26.7 \%)$. The most informative marker of oxidative stress among all ARDS risk patients is GPx, which correlates with Pa02/ Fi02 and oxidation index $(R=-0.52 ; p=0.045$ and $R=0.57 ; p=0.027)$ at the 1st day of observation. At the 4th day of observation $G P x$ shows statistically significant relation with the level of PEEP $(R=0.57 ; p=0.033)$. Among ARDS patients we have found correlation between $\mathrm{PaO2} / \mathrm{FiO2}$ ratio and MDA+ HNE plasma levels $(\mathrm{R}=0.69 ; \mathrm{p}=0.026)$ at the 1 st day of observation.

Conclusion. Reactive oxygen substances causing oxidative stress shows a dynamic changes in ARDS patients. The changes of some oxidative markers are related to the increased level of hypoxemia and PEEP used in treatment of ARDS patients.

Key words: Acute respiratory distress syndrome; acute lung injury; oxidative stress, reactive oxygen species.

\section{INTRODUCTION}

Patients in the intensive care unit (ICU) are likely to suffer from acute respiratory failure (ARF) with a risk of developing acute lung injury (ALI) and its more severe condition, acute respiratory distress syndrome (ARDS) with $30-50 \%$ mortality $(1,2)$. The incidence of ARDS has almost doubled, but hospital mortality has decreased during the 23 years of observation (3).

Patients with ARF, and particularly those diagnosed with ARDS, represent a great economic burden because of the requirement of long lasting ventilatory support, eventually including extracorporeal membrane oxygenation (ECMO) and other organ replacement therapy strategies due to developing multiorgan disfunction syndrome (MODS).

The pathogenesis of ARDS is complex, and unfortunately, the development of this syndrome in an individual patient is difficult to recognize. Dominant role in ARDS pathophysiology plays imbalance between oxidant and antioxidant species. Attention towards reactive oxygen species (ROS) is increasing since so many physiological and pathophysiological phenomena are related to modifications of the redox state of the cells $(4,5)$.
Evidence of massive oxygen stress is well established in adult critical illnesses characterized by tissue ischemia reperfusion injury and by intense systemic inflammatory response in such conditions as sepsis and ARDS (6-8). ROS can initiate cellular tissue damage by modifying lipids, proteins and DNA, which can induce a generation of secondary reactive species, leading to cell death by apoptosis.

Lipid peroxidation is a complex process where polyunsaturated fat in the phospholipids of cellular membranes reacts with oxygen to form lipid peroxides and hydroperoxides, which can decompose to form other products including alkanals, alkenals, hydroxyalkenals, malondialdehyde (MDA), reactive carbonyl intermediates such us $\alpha, \beta$-unsaturated aldehydes (4HNE). Thiobarbituric acid reactive species (TBARS), Malondialdehyde is the indicator, which can be used to detect lipid peroxidation. The lipid peroxidation's reaction in biological membranes causes impairment of membrane functioning, decreases fluibility, inactivation of membrane-bound receptors and enzymes and increases non-specific permeability to ions (9).

Free radicals can be decomposed by several 
metalloenzymes (e.g., superoxide dismutase, glutathione peroxidase, catalase,) as well as by the non-enzymatic antioxidant defense system. Glutathioneperoxidase (GPx) is the enzyme, which acts on degradation of them to less harmful products. $(10,11)$.

Nevertheless, results are controversial and currently reduction of antioxidant capacity to outcome is not clearly proven in ARDS patients. Moreover, antioxidants are not well investigated as early prognostic and diagnostic markers for ARDS patients.

\section{AIM OF THE STUDY}

The aim of the study was to investigate the influence of oxidative stress species on developing of acute respiratory distress syndrome in patients at risk.

\section{MATERIALS AND METHODS}

The study was conducted in Pauls Stradins Clinical University Hospital ICU during 6 months in 2013 and approved by ethics committee.

There were included 15 ARDS risk patients over 18 years of age with mechanical lung ventilation (MLV) over 24 hours and massive blood component transfusions, acute severe pancreatitis, pneumonia or sepsis. There were excluded patients with chronic heart, liver and kidney diseases as well as patients with tumor or immunodeficiency syndrome.

Biological samples were taken three times during observational period from the time of inclusion to the study. First sample were taken just exactly after inclusion, second sample- on $4^{\text {th }}$ day after inclusion and the last sample- on $7^{\text {th }}$ day after inclusion.

The developing of ARDS were diagnosed using revised diagnostic criteria according to the Berlin definition, where ALI is defined as mild form of ARDS, as depicted in Table 1 (12). Table 1 distinguishes between three categories of mild, moderate and severe ARDS to provide better separation of prognosis and interventional decisions. Mild ARDS criteria: $200 \mathrm{~mm} \mathrm{Hg} \leq \mathrm{PaO} 2 / \mathrm{FiO} 2$ $\leq 300 \mathrm{~mm} \mathrm{Hg}$ with CPAP or PEEP $\geq 5 \mathrm{~cm} \mathrm{H} 2 \mathrm{O}$. Moderate ARDS criteria: $100 \mathrm{~mm} \mathrm{Hg} \leq \mathrm{PaO} 2 / \mathrm{FiO} 2 \leq 200 \mathrm{~mm} \mathrm{Hg}$ with PEEP $\geq 5 \mathrm{~cm}$ H2O. Severe ARDS criteria: $\mathrm{PaO} 2 /$ FiO2 $\leq 100 \mathrm{~mm} \mathrm{Hg}$ with PEEP $\geq 5 \mathrm{~cm} \mathrm{H} 2 \mathrm{O}$.

Acute onset is defined as a condition developing within one week of a known clinical respiratory failure. Chest radiograph should include "diffuse" bilateral opacities consistent with pulmonary edema that is not fully explained by effusions, lung collapse, or nodules/ masses. CT scan abnormalities are not included in the definition (Table 1).

Demographic and clinical data of each patient were observed- age, gender, diagnosis, co-morbidities, ventilator settings and outcome. Daily monitoring including heart rate (HR) $\mathrm{x} / \mathrm{min}$, central venous pressure (CVP) mmHg, mean arterial pressure (MAP) $\mathrm{mmHg}$, diuresis $\mathrm{ml} / 24 \mathrm{~h}$. Routine measurements: blood gases, blood, biochemical analysis. Oxygenation index was calculated as well as $\mathrm{PaO} 2 /$ FiO2.

The list of the investigated reactive oxygen species is the following. Lipid peroxidation (LPO) products as malondialdechide (MDA) and 4- hydroxynonenal (HNE) is detected in plasma using manual spectrophotometry with Microplate reader Infinity 2000 (Tecan Ltd.) and LPO Microplate Based Assay Kit (Oxford Biomedical Research, USA). The method in this assay is designed to assay either MDA alone (in hydrochloric acid) or MDA in combination with HNE (in methanesulfonic acid) $(13,14)$.

The thiobarbituric acid reactive substances (TBARS) is detected in plasma using manual spectrophotometry with Microplate reader Infinity 2000 (Tecan Ltd.) and TBARS A ssay kit (Cell Biolabs, Inc., USA) (15).

Free radicals as nitric oxide (NO) is detected in plasma using manual spectrophotometry with Microplate reader Infinity 2000 (Tecan Ltd.) and QuantiChromTM Nitric Oxide Assay Kit (GENTAUR Molecular Products, USA). Nitric oxide is rapidly oxidized to nitrite and nitrate which are used to quantitate NO production (16- 18).

Antioxidant defence system was characterized by glutathione reductase (GR) and glutathione peroxidase (GPx). Glutathione reductase is detected in plasma using automatic spectrophotomery according to the manufacturer's instructions for analyser RX Daytona (Randox Laboratories, Ltd., Crumlin, UK). Glutathione peroxidase is detected in heparinised whole blood using automatic spectrophotometry with RX Daytona analyser (Randox Laboratories, Ltd., Crumlin, UK). Glutathione peroxidase catalyses the oxidation of Glutathione (GSH) by cumenehydroperoxide. In the presence of Glutathione reductase (GR) and NADPH the oxidised Glutathione (GSSG) is immediately converted to reduced form with a concomitant oxidation of NADPH to NADP+ $(19,20)$.

Data were analyzed using SPSS statistical program version 21.0. The obtained results were compared using Pearson's Correlation test. The statistically valid $\mathrm{p}$ value was $<0.05$.

\section{RESULTS}

Among included patients $82.4 \%$ were males with the mean age 49.3 years, for female 67 years (Table 2). There were included patients with the risk factors of developing ARDS, such as acute severe pneumonia, pancreatitis, sepsis or diseases leading to the massive blood loss. Among those the most frequent diagnosis was acute severe pneumonia $(n=5 ; 33.3 \%)$, followed by patients with sepsis $(n=4 ; 26.7 \%)$ and acute severe pancreatitis $(n=4 ; 26.7 \%)$. Small number of patients were observed with the severe digestive tract bleeding leading to the massive blood loss $(n=2 ; 13.3 \%)$. The most severe stage of ARDS was observed in patients with acute pneumonia and sepsis. At the first day of observation there were found five patients with non ARDS, three patients with mild stage of ARDS, five patients with moderate ARDS and two patients with severe ARDS. The situation was changed until the 4th day of observation, where we found three non ARDS patients, five patients with mild ARDS, five patients with moderate ARDS and two patients with severe ARDS as 
previously. Among the ARDS patients three were not survived until 7 th day of observation.

The only one marker of oxidative stress among all ARDS risk patients is GPx, which correlates with $\mathrm{PaO} 2 / \mathrm{FiO} 2$ and oxidation index $(\mathrm{R}=-0.52 ; \mathrm{p}=0.045$ and $\mathrm{R}=0.57$; $\mathrm{p}=0.027$ ) at the 1st day of observation. At the 4th day of observation GPx shows statistically significant relation with PEEP $(\mathrm{R}=0.57 ; \mathrm{p}=0.033)$.

Among ARDS patients (non ARDS patients were excluded) we have found statistically significant correlations at the lst day of observation. One of the most important diagnostic criteria for ARDS is ratio $\mathrm{PaO} 2 / \mathrm{FiO} 2$, which correlates with increased levels of MDA+ HNE (Table 2) in plasma $(R=0.69 ; p=0.026)$. On the other hand the same marker shows statistically significant correlation with the stage of ARDS $(\mathrm{R}=$ $-0.64 ; p=0.048)$. The other marker is TBARS, which is connected with the poor outcome $(\mathrm{R}=-0.8$; $\mathrm{p}=0.006)$. At the 4th day TBARS shows relation with the $\mathrm{PaO} 2 /$ FiO2 $(\mathrm{R}=-0.66 ; \mathrm{p}=0.05)$, oxidation index $(\mathrm{R}=0.68$; $\mathrm{p}=0.042)$ and PEEP levels in ARDS patients $(\mathrm{R}=0.73$; $\mathrm{p}=0.025)$, what could be explained by severe health condition.

Nitrogen oxide also showed statistically significant correlation with respiratory function parameters, but the same relation was observed in non ARDS patients as well.

\section{DISCUSSION}

Acute respiratory distress syndrome is a common cause for mechanical lung ventilation and ICU treatment. The most common causes of developing ARDS are acute severe pneumonia, sepsis, pancreatitis and massive blood component transfusions. Patients with severe pneumonia and pancreatitis are more likely to suffer from severe ARDS. The same trends were found in our study as well. Males are more at risk of ARDS development compared with females according to our results. In comparison by Sigurdsson et al. the ARDS population is similar in males and females (3). Among those at risk ten of fifteen patients were with the diagnosed different stages ARDS at the first day of observation. This is a high number of cases during few months study period, but it could be explained by specific risk population.

According to our results one of the most important diagnostic criteria for ARDS is ratio $\mathrm{PaO} 2 / \mathrm{FiO} 2$, which correlates with increased levels of MDA+ HNE in plasma $(\mathrm{R}=0.69 ; \mathrm{p}=0.026)$ at the 1 st day of observation. On the other hand the same marker shows statistically significant correlation with the severity of ARDS $(R=-0.64 ; p=$ 0.048 ). In addition oxidative stress plays an important role in sepsis (21). Previous studies confirmed severe oxidative stress in sepsis patients demonstrating reduced plasma, total antioxidant capacity, and elevated levels of malondialdehyde and 4-hydroxynonenal (22). Another group of reactive oxygen species is thiobarbituric acid reactive species which shows a significant relation with oxidation index $(R=0.68 ; p=0.042)$ and PEEP levels in ARDS patients $(R=0.73 ; p=0.025)$ at the 4 th day of observation. Other researchers also have found that the MDA and TBARS levels are higher in ARDS patients or in patients at risk of developing ARDS than in those of healthy ones (23).

To evaluate oxidative stress markers as predictors of ARDS severity or outcome we need to continue our studies in local population.

\section{CONCLUSIONS}

Reactive oxygen substances causing oxidative stress shows a dynamic changes in ARDS patients and in patients at risk. Severe health condition of ARDS patients resulted in increased level of PEEP used in treatment and is related to the high level of oxidative stress markers.

\section{Conflict of interest: None}

\section{REFERNCES}

1. Bernard GR, Artigas A, Brigham KL, Carlet J, Falke K, Hudson L, Lamy M, Legall JR, Morris A, Spragg R: The American-European Consensus Conference on ARDS. Definitions, mechanisms, relevant outcomes, and clinical trial coordination. American journal of respiratory and critical care medicine 1994, 149(3 Pt 1):818-824.

2. Ferguson ND, Frutos-Vivar F, Esteban A, Gordo F, Honrubia T, Penuelas O, Algora A, Garcia G, Bustos A, Rodriguez I: Clinical risk conditions for acute lung injury in the intensive care unit and hospital ward: a prospective observational study. Critical care (London, England) 2007, 11(5):R96.

3. Sigurdsson M.I., Sigvaldason K., Gunnarsson T.S., Moller A., Sigurdsson G.H. Acute respiratory distress syndrome: nationwide changes in incidence, treatment and mortality over 23 years. Acta Anaesthesiol Scand 2013; 57: 37-45.

4. Jun S, Pierce A, Dory L: Extracellular superoxide dismutase polymorphism in mice: Allele-specific effects on phenotype. Free radical biology $\delta$ medicine 2010, 48(4):590-596.

5. Gao L, Barnes KC: Recent advances in genetic predisposition to clinical acute lung injury. American journal of physiology Lung cellular and molecular physiology 2009, 296(5):L713-725.

6. Crimi E, Sica V, Williams-Ignarro S, Zhang $\mathrm{H}$, Slutsky AS, Ignarro LJ, Napoli C: The role of oxidative stress in adult critical care. Free radical biology \& medicine 2006, 40(3):398-406.

7. Kumar KV, Rao SM, Gayani R, Mohan IK, Naidu MU: Oxidant stress and essential fatty acids in patients with risk and established ARDS. Clinica chimica acta; international journal of clinical chemistry 2000, 298(1-2):111-120.

8. Bowler RP, Velsor LW, Duda B, Chan ED, Abraham E, Ware LB, Matthay MA, Day BJ: Pulmonary edema fluid antioxidants are depressed in acute lung injury. Critical care medicine 2003, 31(9):23092315. 
9. Palmieri B, Sblendorio V: Oxidative stress tests: overview on reliability and use: European Review for Medical and Pharmacological Sciences 2007; 11 : 309-342.

10. Cui K, Luo X, Xu K, Ven Murthy MR. Role of oxidative stress in neurodegeneration: recent developments in assay methods for oxidative stress and nutraceutical antioxidants. Prog Neuropsychopharmacol Biol Psychiatry. 2004; 28:771-799.

11. Wilcox JK, Ash SL, Catignani GL. Antioxidants and prevention of chronic disease. Crit Rev Food Sci Nutr. 2004; 44:275-295.

12. Ranieri VM, Rubenfeld GD, Thompson BT, Ferguson ND, Caldwell E, Fan E, Camporota L, Slutsky AS: Acute respiratory distress syndrome: the Berlin Definition. JAMA : the journal of the American Medical Association 2012, 307(23):2526-2533.

13. Esterbauer and Cheesman, Meth. Enzymol. 186: 407-421, 1990.

14. Janero, et al., Free Rad. Biol. Med. 9: 515-540, 1990.

15. Armstrong, D. and Browne, R. Free Radicals in Diagnostic Medicine. 1994. 366: 43-58.

16. BolanderJr, F. F. The compartmentalization of prolactin signaling in the mouse mammary gland. Mol. Cell. Endocrinol 245:105-110, 2005.

17. Bulau, P. et al. Analysis of methylarginine metabolism in the cardiovascular system identifies the lung as a major source of ADMA. Am J Physiol Lung Cell MolPhysiol 292: L18-L24, 2007.
18. Hasegawa, K. et al. Role of asymmetric dimethylarginine in vascular injury in transgenic mice overexpressing dimethylarginiedimethylaminohydrolase.Circ Res. $101(2): e 2-10,2007$.

19. Goldberg DM, Spooner RJ. Assay of glutathione reductase. Bergmeyen $\mathrm{HV}$ eds. Methods of enzymatic analysis 3rd ed. 1983:258-265 VerlagChemie Deerfield Beach, F.

20. Paglia D.E., Valentine W.N. J.Lab.Clin.Med. 1967;70: 158.

21. Crimi E, Sica V, Slutsky AS, Zhang H, WilliamsIgnarro S, Ignarro LJ, et al. Role of oxidative stress in experimental sepsis and multisystem organ dysfunction. Free Radic Res 2006; 40 : 665-72.

22. Alonso de Vega JM, Díaz J, Serrano E, Carbonell LF. Oxidative stress in critically ill patients with systemic inflammatory response syndrome. Crit Care Med 2002; 30 : 1782-6.

23. Marczin N., Kharitonov A., Yacoub H., Barnes J. Disease markers in exhaled breath. 2005. Volume 170, p. 346.

\section{Address:}

Marina Sarkele

Department of Anaesthesiology and Reanimatology

Pauls Stradins Clinical University Hospital

13 Pilsonu street

Riga, Latvia, LV-1002

E-mail: marina.sarkele@stradini.lv 
Table 1. The Berlin Definition of ARDS (9)

\begin{tabular}{|c|c|}
\hline \multicolumn{2}{|r|}{ The Berlin Definition of Acute Respiratory Distress Syndrome } \\
\hline & Acute Respiratory Distress Syndrome \\
\hline Timing & Within 1 week of a knon clinical insult or new or worsening respiratory symptoms \\
\hline Chest imaging ${ }^{\mathrm{a}}$ & Bilateral opacities - not fully explained by effusions, lobar/lung collapse, or nodules \\
\hline Origin of edema & $\begin{array}{l}\text { Respiratory failure not fully explained by cardiac failure or fluid overload } \\
\text { Need objective assessment (eg, echocardiography) to exclude hydrostatic edema if no } \\
\text { risk factor present }\end{array}$ \\
\hline $\begin{array}{l}\text { Oxygenation } \\
\text { Mild }\end{array}$ & $200 \mathrm{~mm} \mathrm{HG}<\mathrm{PaO}_{2} / \mathrm{FIO}_{2} \leq 300 \mathrm{~mm} \mathrm{Hg}$ with PEEP or CPAP $\geq 5 \mathrm{~cm} \mathrm{H}_{2} \mathrm{O}^{\mathrm{c}}$ \\
\hline Moderate & $100 \mathrm{~mm} \mathrm{Hg}<\mathrm{PaO}_{2} / \mathrm{FIO}_{2} \leq 200 \mathrm{~mm} \mathrm{Hg}$ with $\mathrm{PEEP} \geq 5 \mathrm{~cm} \mathrm{H}_{2} \mathrm{O}$ \\
\hline Severe & $\mathrm{PaO}_{2} / \mathrm{FIO}_{2} \leq 100 \mathrm{~mm} \mathrm{Hg}$ with PEEP $\geq 5 \mathrm{~cm} \mathrm{H}_{2} \mathrm{O}$ \\
\hline
\end{tabular}

Abbrevations: CPAP, continuous positive airway pressure; $\mathrm{FIO}_{2}$, fraction of inspired oxygen; $\mathrm{PaO}_{2}$, partial pressure of arterial oxygen; PEEP, positive end-expiratory pressure.

${ }^{a}$ Chest radiograph or computed tomography scan.

${ }^{\mathrm{b}}$ If altitude is higher than $1000 \mathrm{~m}$, the correction factor should be calculated as follows: $\left[\mathrm{PaO}_{2} / \mathrm{FIO}_{2} \mathrm{x}\right.$ (barometric pressure/ 760)].

${ }^{c}$ This may be delivered $\mathrm{n}$ oninvasively in the mild acute respiratory distress syndrome group.

Table 2. Patients at risk of developing ARDS

\begin{tabular}{|c|c|c|c|c|c|c|c|c|}
\hline Nr. & Gender & Age & Diagnosis & Outcome & Day 1 & $\begin{array}{c}\mathrm{MDA}+\mathrm{HNE} \\
\mathrm{mkM}\end{array}$ & Day 4 & $\begin{array}{c}\mathrm{MDA}+\mathrm{HNE} \\
\mathrm{mkM}\end{array}$ \\
\hline 1. & M & 40 & Pneumonia & Survived & Severe ARDS & 1.99 & Severe ARDS & 2.65 \\
\hline 2. & M & 64 & Pneumonia & Survived & $\begin{array}{l}\text { Moderate } \\
\text { ARDS }\end{array}$ & 4.14 & Mild ARDS & 3.38 \\
\hline 3. & M & 34 & Sepsis & Non survived & Non ARDS & 2.32 & $\begin{array}{c}\text { Moderate } \\
\text { ARDS }\end{array}$ & 3.05 \\
\hline 4. & M & 53 & Blood loss & Survived & Non ARDS & 5.34 & Non ARDS & 4.09 \\
\hline 5. & M & 75 & Pancreatitis & Non survived & Mild ARDS & 6.21 & Mild ARDS & 2.37 \\
\hline 6. & M & 67 & Sepsis & Survived & $\begin{array}{c}\text { Moderate } \\
\text { ARDS }\end{array}$ & 2.93 & Mild ARDS & 2.78 \\
\hline 7. & M & 66 & Pneumonia & Non survived & Severe ARDS & 4.24 & Severe ARDS & 3.26 \\
\hline 8. & M & 41 & Pneumonia & Survived & Non ARDS & 3.05 & Non ARDS & \\
\hline 9. & M & 67 & Sepsis & Survived & Mild ARDS & 3.66 & Mild ARDS & 4.13 \\
\hline 10. & F & 33 & Pancreatitis & Survived & $\begin{array}{c}\text { Moderate } \\
\text { ARDS }\end{array}$ & 5.47 & $\begin{array}{c}\text { Moderate } \\
\text { ARDS }\end{array}$ & 4.79 \\
\hline 11. & M & 45 & Blood loss & Survived & Non ARDS & 11.68 & $\begin{array}{l}\text { Moderate } \\
\text { ARDS }\end{array}$ & 13.66 \\
\hline 12. & M & 51 & Pancreatitis & Survived & $\begin{array}{c}\text { Moderate } \\
\text { ARDS }\end{array}$ & 5.32 & Mild ARDS & 4.18 \\
\hline 13. & M & 44 & Sepsis & Survived & Non ARDS & 4.52 & $\begin{array}{c}\text { Moderate } \\
\text { ARDS }\end{array}$ & 3.19 \\
\hline 14. & M & 44 & Pneumonia & Survived & $\begin{array}{c}\text { Moderate } \\
\text { ARDS } \\
\end{array}$ & 4.1 & $\begin{array}{c}\text { Moderate } \\
\text { ARDS }\end{array}$ & 3.92 \\
\hline 15. & M & 33 & Pancreatitis & Survived & Mild ARDS & 4.66 & Non ARDS & 4.37 \\
\hline
\end{tabular}

